Cahiers $d u$ MONDE RUSSE

\section{Cahiers du monde russe}

Russie - Empire russe - Union soviétique et États indépendants

$47 / 4 \mid 2006$

Varia

\title{
Instituty upravlenija kul'turoj v period stanovlenija : 1917-1930-e gg
}

\section{Alexandre Sumpf}

\section{OpenEdition}

\section{Journals}

Édition électronique

URL : https://journals.openedition.org/monderusse/4702

DOI : $10.4000 /$ monderusse.4702

ISSN : $1777-5388$

\section{Éditeur}

Éditions de l'EHESS

\section{Édition imprimée}

Date de publication : 30 décembre 2006

Pagination : 826-828

ISBN : 978-2-7132-2098-2

ISSN : $1252-6576$

Référence électronique

Alexandre Sumpf, «Instituty upravlenija kul'turoj v period stanovlenija : 1917-1930-e gg », Cahiers du monde russe [En ligne], 47/4 | 2006, mis en ligne le 03 juillet 2009, consulté le 03 septembre 2022 URL : http://journals.openedition.org/monderusse/4702; DOI : https://doi.org/10.4000/monderusse. 4702

Ce document a été généré automatiquement le 3 septembre 2022.

Tous droits réservés 


\title{
Instituty upravlenija kul'turoj v period stanovlenija : 1917-1930-e gg
}

\author{
Alexandre Sumpf
}

\section{RÉFÉRENCE}

Instituty upravlenija kul'turoj v period stanovlenija : 1917-1930-e gg. Partijnoe rukovodstvo, gosudarstvennye organy upravlenija : Shemy [Les institutions de direction de la culture dans la période d'établissement : 1917-1930 La direction par le parti, les organes étatiques d'administration : Schémas]. Moscou : ROSSPEN, 2004, 312 p.

1 «Ce livre représente le rêve tant convoité de tout spécialiste qui travaille sur la construction culturelle de la nation et de l'État ». Cette première phrase de l'ouvrage et de l'introduction de T.M. Gorjaeva résonne comme une incantation et annonce un programme particulièrement ambitieux. Le seul titre de l'ouvrage frappe d'ailleurs tant par son souci d'exhaustivité que par l'absence de mention de tout auteur, comme si l'individu se devait de s'effacer derrière l'institution. La coordinatrice scientifique de ce projet lie ainsi, dans un préambule intitulé "L'harmonie mesurée par l'algèbre ", l'universalité du sujet choisi - les structures étatiques du monde moderne - et celle de la modélisation par « schémas » structurels. En effet, largement diffusé dès la fondation du régime soviétique par des bolcheviks sensibles à la modernité scientifique, le schéma comporte un degré séduisant de perfection.

2 Les historiens des premières années soviétiques ont tous tenté, à un moment ou à un autre, de délimiter aussi catégoriquement le champ mal nivelé sur lequel ils exercent leur expertise. C'est un poncif de dire que l'histoire institutionnelle de l'Union soviétique des années 1920 (et 1930, et des autres décennies, d'ailleurs) est un imbroglio total. L'assertion mérite pourtant réflexion: n'est-ce pas le cas de toute histoire des institutions d'un État moderne? Cependant, s'entendra-t-on répondre, le «cas soviétique " paraît plus " grave ». La bipolarité du sous-titre souligne celle, classique en histoire soviétique, de l'État et du parti. Or tous deux entremêlent à tel point leurs 
sphères de compétence qu'il est souvent impossible de déterminer où se situe l'instance, le moment ou l'argument de décision.

3 Certains soviétologues ont vu dans cette complexité un critère de comparaison (au sens large) avec d'autres régimes «totalitaires» (Allemagne nazie); d'autres, au contraire, y ont décelé une spécificité propre au seul système soviétique. Pour tous, il s'agit d'un critère d'évaluation du régime dit "stalinien ", à l'œuvre dans les années 1930. C'est dans ce lourd et ancien contexte historiographique que se situe la tentative de nos collègues russes, qu'il est temps d'aborder après ce détour obligé. Une dernière remarque, toutefois, sur la soi-disant particularité de l'exemple soviétique : ne serait-elle pas une construction commode qui structure l'analyse au premier degré, mais gêne considérablement tout approfondissement?

4 Afin d'apporter ici de modestes éléments de réponse, revenons donc au contenu de l'ouvrage. Étant entendu qu'il serait aussi long qu'ingrat de proposer, quinze années à peine après la chute de l'Union soviétique, un panorama schématisé complet de l'ensemble du "système soviétique» en formation entre Octobre et le "grand tournant ", un choix s'imposait. Les recherches historiques effectuées par T. M. Gorjaeva, directrice des Archives nationales de l'art et de la littérature (RGALI), tout autant que la vogue de «l'histoire culturelle » qui a aussi touché la soviétologie, expliquent sans doute le coup de projecteur proposé sur la « culture » soviétique.

Dans leur plan, les auteurs de l'ouvrage distinguent, fort logiquement, les « organes de direction supérieure " (le Comité central du parti, en première partie) du "système de direction de l'État» (en seconde partie). Ce dernier se subdivise de façon à la fois hiérarchique et chronologique : on passe du commissariat du peuple à l'Éducation ou Narkompros (deux chapitres) au Comité artistique du Conseil des commissaires du peuple dans les années 1930, avant de se pencher successivement sur les cas (vraiment) particuliers du cinéma et de l'ensemble presse/édition.

Chacun de ces six chapitres précédés d'une introduction consiste en schémas successifs, soit respectivement: 13 (Comité central, 1920-1948), 18 (Narkompros, 1917-1921), 31 (Narkompros, 1922-1938), 25 (Comité artistique, 1936-1940), 16 (cinématographie, 1922-1938) et 57 (presse et édition, 1919-1940). Les introductions, globalement exhaustives et claires, poursuivent dans le même esprit l'inégalable travail d'érudition de la défunte T.P. Koržihina. Toutefois, un commentaire s'impose ici sur les bornes chronologiques adoptées et sur la densité informative de chaque section.

7 Tout d'abord, le caractère exceptionnel de l'information disponible sur les instances de contrôle de la presse et de l'édition doit être relativisé, tant cette information dépend du biais que représente l'abondance variable des documents - elle-même tributaire à la fois des politiques de conservation ou de dissimulation et des axes de sondage des collaborateurs de l'ouvrage. Certes, la succession temporelle des instances ad hoc du parti ne connaît aucune rupture, mais l'ajout d'une note précisant que certains fonds sont accessibles (APO, 1920-1928), tandis que d'autres ont apparemment disparu (APPO, 1928-1930), aurait permis de mieux baliser les futures recherches dont cet ouvrage se veut un guide.

8 D'autre part, les dates choisies pour établir les schémas suivent généralement les mouvements de réorganisation des institutions. À la suite des schémas du Narkompros, un texte explique ainsi en détail les " changements de structure ", souvent contradictoires et temporaires. Cette partie, appuyée sur la litanie des références précises des documents consultés, est tout à fait convaincante et éclairante. Notons toutefois qu'elle contrevient 
en soi à l'esprit "géométrique " de l'ouvrage. Surtout, une ébauche de comparaison entre chronologies fines, propres à chaque institution distincte, aurait facilité la lecture et même donné un sens aux choix imposés au lecteur. En effet, pour prendre un exemple qui nous est bien connu, celui de la Direction générale de l'éducation politique (Glavpolitprosvet), le schéma de la page 91, s'il est historiquement juste, est en fait la correction d'une première ébauche datée de la fondation de l'institution le 12 novembre 1920. Voilà pour l'exhaustivité. Le deuxième schéma, p. 98, est bien débattu en avril 1922, mais n'est finalement proposé par décret que le 26 octobre de la même année..., comme en témoigne le troisième schéma (p. 106-107), daté lui de 1923. Voilà pour la chronologie. Le quatrième schéma, de 1925 (p. 117), est le dernier de l'institution dans l'ouvrage, alors que le Glavpolitprosvet n'est supprimé qu'à l'été 1930. Seule une lecture attentive des schémas généraux du Narkompros de 1928 (p.124) et de 1930 (p. 133) permet de déceler l'existence et la disparition de l'institution. Ces lacunes s'expliquent bien aisément : le fonds du Glavpolitprosvet au GARF est très incomplet après 1925.

Mais ces insuffisances correspondent aussi à un défaut plus général de l'ouvrage. Chaque schéma est accompagné d'une liste plus ou moins complète de responsables des directions (upravlenija), départements (otdely), divisions (podotdely), secteurs (sektory) et sections (sekcii) - d'ailleurs réunis en fin de volume dans un index très appréciable. Or, à lui seul, l'organigramme complet de la maison d'édition d'État Gosizdat en 1924 ne nécessite pas moins de 17 schémas..., mais seuls dix responsables principaux ont été reportés. Notre propre expérience de la «nébuleuse du Narkompros » en général, et du Glavpolitprosvet en particulier, nous apprend que bien d'autres noms auraient pu être reportés si d'autres fonds d'archives avaient été consultés. Plus en profondeur, il aurait fallu insister bien davantage sur la dimension humaine de cette histoire des institutions soviétiques (de la culture). Entre la création d'un secteur, le recrutement et l'entrée en fonction de son responsable, un délai explique parfois l'absence de nom dans des cases nouvellement ouvertes.

Ces cases, ces schémas, correspondent-ils finalement à une quelconque réalité? La question méritait d'être posée de manière préalable et débattue au fil des pages d'un ouvrage qui fait date, moins par son apport à la connaissance historique que parce qu'il représente une tentative originale (et vaine ?) de rationaliser l'exploitation des masses de documents accessibles dans les archives. 